\title{
Relação entre ensino e literatura: um olhar para a dimensão da ação e atuação docente
}

\section{The relationship between teaching and literature: a look at the dimension of action and teaching performance}

\author{
Rita Cássia Oliveira ${ }^{1}$ \\ Ludmila Magalhães Naves ${ }^{2}$ \\ Ilsa do Carmo Vieira Goulart ${ }^{3}$
}

\section{Resumo}

Pautado na dimensão enunciativa-discursiva da linguagem, o presente texto considera as palavras escritas como forma de expressividade e interlocução entre leitor e texto. $\mathrm{O}$ letramento literário é visto como prática de apropriação da literatura enquanto linguagem, de produção de sentidos, de vivência literária, sem restringir-se ao período escolar, o que ocorre em diferentes instâncias sociais. Entretanto, a escola se mostra um espaço de gerenciamento de ações leitoras, o que permite experiências significativas com a literatura. Diante disso, temse por finalidade refletir sobre a relação entre ensino e literatura, por meio de um relato de experiência de ações e práticas que envolvem a leitura literária, realizadas no contexto de sala de aula. A partir da descrição do relato de experiências, desenvolvidas por uma professora do $2^{\circ}$ ano do Ensino Fundamental, com as crianças em processo de alfabetização, apresenta-se uma análise reflexiva das ações de leitura literária, subsidiada pelas proposições de Cosson (2014; 2016), em interlocução com autores que discutem a temática. Assim, busca-se uma aproximação entre teoria e prática, ressignificando o papel da leitura literária na escola, de modo a dar visibilidade ao professor como mediador no processo de formação de leitores. Como resultado, destaca-se que as mudanças referentes ao trabalho pedagógico com a leitura literária, desenvolvidas pela professora, mostraram-se coerentes com as características fundamentais enfatizadas sobre o letramento literário por Cosson. A partir dessa reflexão, constatou-se que foram propostas ações e atuações de práticas da leitura, que favoreceram e encorajaram o desenvolvimento de estratégias de leitura pela criança como sujeito-leitor.

Palavras-chave: Leitura literária; Letramento literário; Estratégias de leitura; Produção de sentidos; Professor-mediador.

\footnotetext{
Abstract

${ }^{1}$ Mestra em Educação; Universidade Federal de Lavras, Lavras/MG, Brasil, e-mail: rita-coliver@hotmail.com

${ }^{2}$ Mestra em Educação; Universidade Federal de Lavras, Lavras/MG, Brasil, e-mail: ludnaves@gmail.com

${ }^{3}$ Doutora em Educação; Universidade Federal de Lavras, Lavras/MG, Brasil, e-mail: ilsa.goulart@ufla.br
} 
Based on the enunciative-discursive dimension of language, this text considers written words as a form of expressiveness and dialogue between reader and text. Literary literacy is seen as a practice of appropriating literature as a language, of producing meanings, of literary experience, without being restricted to the school period, which occurs in different social instances. However, the school shows itself as a space for managing reader actions, which allows significant experiences with the literature. So, the purpose is to reflect on the relationship between teaching and literature, through an experience report of actions and practices that involve literary reading, performed in the classroom context. Based on the description of the experiences report, developed by a 2 nd grade elementary school teacher, with children in the process of alphabetization, a reflexive analysis of literary reading actions is presented, supported by Cosson's propositions $(2014 ; 2016)$, and other authors who discuss about the subject. Therefore, an approximation between theory and practice is sought, giving a new meaning to the role of literary reading in school, in order to enhance the role of the teacher as a mediator in the process of building new readers. As a result, it is highlighted that the changes regarding the pedagogical work with literary reading, developed by the teacher, were consistent with the fundamental characteristics emphasized on literary literacy by Cosson. From this reflection, it was found that actions and reading practices were proposed, which helped and encouraged the development of reading strategies by the child as reader.

Keywords: Literary reading; Literary literacy; Reading strategies; Construction of meaning; Teacher-mediator.

\title{
Considerações iniciais
}

\author{
Ter em mãos um livro literário é defrontar-se com o desequilíbrio. \\ É bom que assim seja. Capaz de inaugurar reflexões, \\ a literatura nos estimula a buscar outros prumos, a perseguir outras ilusões, \\ a nos desdobrarmos sobre nossos limites e \\ descobrirmos a fragilidade como sendo a nossa condição possível. \\ Queirós (2012, p. 91)
}

A reflexão proposta, neste texto, pauta-se na dimensão da palavra enquanto linguagem constitutiva de expressividade, de comunicação, de interação com o mundo exterior e com a interioridade do sujeito, de dialogização enunciativa-discursiva, segundo Bakhtin (2012, 2003). Se a literatura, enquanto forma de expressão da linguagem, ao se constituir de palavras, desencadeia-se a cada obra vertentes enunciativas, que exigem do sujeito-leitor um posicionamento, uma ação responsiva que ultrapassa os delimites impostos pelo código linguístico. No entanto, a dimensão literária ultrapassa a esfera lexical, podendo se manifestar em modos diferenciados da linguagem, em que o texto se mostra na pluralidade, seja escrito, 
oralizado, visual, estático ou em movimento, ou até na hibridização. Com isso, promove-se uma interlocução movida pela dinamicidade da significação, imbricada a partir do que, como, quando, para que e para quem se produz um texto literário, seja por "defrontar-se com o desequilíbrio", seja porque "nos estimula a buscar outros prumos", conforme descreve a epígrafe, a literalidade permite um encontro dialógico entre o sujeito-leitor e o texto.

Se em uma sociedade letrada em que o fazer cotidiano encontra-se permeado por textos, seja escrito ou visual, seja por ações que envolvem atividades de produção escrita, segundo Souza e Cosson (2011), a leitura torna-se uma das competências culturais mais almejadas e valorizadas. Frente à multiplicidade das práticas sociais que envolvem as atividades de leitura e escrita, autores como Street (2014), Rojo (2009), Soares (1999) e Cosson $(2014 ; 2016)$, consideram mais adequado o emprego terminológico "letramentos", por incluir ou abranger as relações com o social, como o midiático, ou com outras áreas do conhecimento, como o letramento matemático, geográfico, científico, etc.

Nessa direção, o letramento literário pertence a essa pluralidade de letramentos, definido por Souza e Cosson (2011), como processo de se apropriar da literatura enquanto linguagem, entendendo que a literatura é um dos usos sociais da escrita. O letramento literário não se constitui na realização de atividades de leitura, mas configura-se em práticas, em ações contínuas, começando na infância e percorrendo por toda nossa vida, por meio da leitura de um romance, de uma novela ou em um evento cultural, entre tantas outras possibilidades de novas experiências literárias (COSSON, 2014, p. 185).

Assim, destaca-se a relevância da atividade de leitura literária para a formação de leitores. E a escola, como instituição social de ensino, tem o papel de desenvolver e ampliar a experiência literária dos alunos, dando lugar especial para a prática vivenciada com o texto. Souza e Cosson (2011, p. 106) apontam que o objetivo maior do letramento literário é nos formar não como "[...] qualquer leitor ou um leitor qualquer, mas um leitor capaz de se inserir em uma comunidade, manipular seus instrumentos culturais e construir com eles um sentido para si e para o mundo em que vive [...]".

Frente à concepção de que a leitura literária pode proporcionar momentos de deleite e de aprendizado, para os sujeitos-leitores envolvidos na ação leitora no contexto escolar, tanto aluno quanto professor são impactados pela leitura. Ao considerar que ocorrem momentos de reflexão sobre o fazer docente, ao ressignificar e repensar o papel da leitura literária em sala de aula, indaga-se: como se daria o letramento literário em salas de alfabetização, onde a 
maioria das crianças ainda não tem o domínio da leitura? De que maneira a leitura literária pode ser explorada em turmas de alfabetização, tornando-se uma experiência prazerosa, ampliando o repertório das crianças e desenvolvendo estratégias que os ajudem na compreensão de textos? Como a ação leitora pode impactar o processo de reflexão da ação e atuação docente?

Nessa perspectiva, assume-se como objetivo refletir sobre a relação ensino e literatura, por meio do relato de experiência de ações e práticas que envolvem a leitura literária realizada no contexto de sala de aula. Para tanto, opta-se por um relato de experiência, a partir da descrição e análise reflexiva das ações de leitura literária desenvolvidas por uma professora do $2^{\circ}$ ano do Ensino Fundamental, com as crianças em processo de alfabetização.

Assim, para melhor disposição textual, a argumentação reflexiva organiza-se em três seções: a primeira discorre sobre a relação entre ensino e literatura, bem como da função do professor e do espaço da leitura literária no contexto escolar; a segunda apresenta uma reflexão sobre ação mediação da leitura literária e a terceira descreve a respeito das experiências com a leitura literária desenvolvidas em sala de aula, de modo específico por uma professora alfabetizadora, em interlocução com a proposição teórica dos autores que discutem a temática.

\section{O papel do professor e o lugar da leitura literária na escola}

O ensino da leitura e da escrita configura-se em uma atribuição da instituição escolar, mas ao se direcionar ao ensino da literatura parece uma responsabilidade que remete ao cargo do professor de língua portuguesa. A questão da relação entre a literatura e escola perpassa discussões teóricas, metodológicas e ideológicas, ao longo da história da educação. De acordo com Zilberman (1988), as reflexões margeiam-se em polaridades decorrentes das perspectivas do ensino da leitura, do ensino da literatura e da função do professor nesse processo. Apesar das efervescentes discussões político-educacionais e estudos acadêmico-científicos sobre literatura e ensino, a prática de leitura literária na escola se efetiva pela atuação do professor.

O professor desenvolve suas propostas pedagógicas a partir dos materiais de leitura que lhe são disponibilizados. Zilberman (1988) e Lajolo (1982) discutem que a prática de 
leitura literária nas escolas ancora-se na realidade brasileira, em grande parte, no livro didático, em textos de autores clássicos da literatura ou em recortes de textos e embora a pesquisa realizada pela autora tenha quase 40 anos, ainda se observam ações pedagógicas direcionadas por essa ótica. Mesmo que se destaquem iniciativas de ações pedagógicas com textos literários, observa-se que as "[...] práticas antigas revestem-se de novas roupagens", segundo Zilberman (1988, p. 113), como o uso do texto restrito a um determinado fim, seja para explorar temas, conceitos, virtudes, seja como mote para o ensino de palavras e sílabas, seja como motivação para a criatividade em atividades de “[...] dramatizações, quadrinizações, jograis, etc.”.

O trabalho pedagógico com e sobre o texto, na esfera escolar, merece algumas reflexões, e nessa direção, Lajolo (2009) discute sobre a utilização ou não do texto em sala de aula, como pretexto para o processo de ensino e aprendizagem. Para a autora, no texto inscrevem-se elementos que vão para além dele mesmo, por possibilitar um encontro de sujeitos: autor e leitor. A escola proporciona um contato com diferentes gêneros textuais, há um caráter coletivo das leituras selecionadas, planejadas e realizadas no contexto da sala de aula, que precisa ter como horizonte o uso social dos textos, em ações pedagógicas organizadas a partir de um contexto. Dessa forma, cada texto traz em si um conjunto de relações, seja com a história do autor, como o momento social/pessoal/político, com o gênero textual, com a composição/estruturação da língua portuguesa, com o leitor, com a situação em que a leitura foi realizada, entre tantas outras possibilidades, "[...] o contexto de um texto é, pois, um emaranhado de fios que se tecem e se soltam, amarrando-se e desamarrando-se uns nos outros". (LAJOLO, 2009, p. 108).

O texto constitui-se de uma concretização do ato discursivo, em que promove a interrelação entre sujeitos, a expressividade e a dialogicidade, segundo Bakhtin (2012, p. 126), o que compõe-se de um dualismo interior e exterior, num movimento de integração entre eles, em que o exterior tem forte impacto na elaboração do ato enunciativo, visto que "[...] a enunciação enquanto tal é puro produto da interação social". A linguagem não é emitida no vazio, como ressalta Brait (2005), mas decorre de uma situação histórica e social concreta do momento em que foi enunciada, ou seja, numa relação dialógica.

Desse modo, a dimensão do texto literário em sala de aula assume outra perspectiva pedagógica, além de uma proposta restrita ao conteúdo curricular. A leitura literária em sala de aula, segundo Lajolo (2009, p. 104), precisa promover o encontro entre leitor e texto, com 
a finalidade de ultrapassar os limites materializados pelo suporte, numa relação em que são “[...] atravessados por todos os lados da história: pela história coletiva, e pela história individual de cada um, e é na interseção dessas histórias, aliás, que se plasma a função autor e leitor".

Nessa direção, a literatura, em conformidade com Cosson (2016), alimenta e exercita a nossa linguagem, pois é constituída materialmente por palavras e a escrita é seu veículo predominante, ocupando, um lugar único em relação à linguagem, “[...] porque conduz ao domínio da palavra a partir dela mesma”. (SOUZA; COSSON, 2011, p. 101)

A literatura possui um papel humanizador, para Candido (2011, p. 177), “[...] toda obra literária é antes de mais nada uma espécie de objeto, de objeto construído; e é grande seu poder humanizador dessa construção". Uma obra se mostra constituída por uma linguagem, que retrata uma dada sociedade ou uma determinada realidade na qual estamos inseridos e, que no seu individual e coletivo, são modificadas, divididas e multiplicadas, dando sentido ao fazer humano (SOUZA; COSSON, 2011). Por suas especificidades, estes autores sinalizam a importância de seu trato de forma adequada na escola, considerando-se que é uma atividade de produção de sentidos e, por isso, extremamente formativa.

Entretanto, a escolarização da literatura muitas vezes se efetiva de maneira inadequada. Isso foi constado por Soares (2011), ao observar que quer fosse na biblioteca, quer fosse na leitura dirigida em sala de aula, quer fosse em atividades leitura formativa ou estudo de textos, essas práticas, ao invés de aproximar os alunos a inserção em práticas sociais de leitura, criavam um distanciamento da obra, desenvolvendo uma resistência ou até mesmo uma aversão ao ato de ler.

A crítica feita por Soares (2011), consiste em afirmar que uma pedagogização mal compreendida da literatura tem desfigurado, desvirtuado e falseado o que é literário ao ser apropriado pela escola para as ações de ensino. Cosson (2016) também se refere sobre a inadequação da escolarização da literatura, apontando alguns aspectos negativos. Estes autores deixaram claro que o tipo de escolarização que, geralmente, tem sido feita nas escolas afasta-se, totalmente, de práticas de leitura eficazes e condizentes ao ideal de leitor que se quer formar.

Contrapondo-se a esse tipo de escolarização da literatura, Cosson (2016) e Souza e Cosson (2011) propõem ações pedagógicas a partir do letramento literário, com ênfase na experiência literária no contexto das práticas escolares de leitura. Com base na proposta de 
letramento literário na escola, recorre-se à perspectiva exposta por Cosson (2014, p. 185), que esclarece que com a proposta de um trabalho com o letramento literário os professores se apropriam de algo, de um tema, de um contexto ou situação e tomam esse algo para si, análogo ao que ocorre quando se lê, por exemplo um poema e percebe-se que “[...] ele nos dá palavras para dizer o que não conseguíamos expressar antes [...]” daquela leitura.

Essa perspectiva de um trabalho com o letramento se constitui, então, em um processo de apropriação, de produção de sentidos, de percepção do que é literário, o que acontece durante toda vida, não se restringindo apenas ao período escolar, mas que, segundo Souza e Cosson (2011, p. 102), “[...] precisa da escola para se concretizar, isto é, ele demanda um processo educativo específico que a mera prática de leitura não consegue sozinha efetivar". Portanto, a escola tem importante papel na formação leitores literários, ensinando aos alunos estratégias de leitura eficazes.

Bem mais do que uma habilidade pronta e acabada de ler textos, o letramento literário se trata de um saber adquirido sobre a literatura, que requer do leitor uma atualização permanente em relação ao universo literário. Desse modo, pode-se afirmar que o letramento literário se constitui como uma experiência de produção sentidos a partir de textos, que por meio de palavras que falam de palavras, explicam Souza e Cosson (2011).

Compreende-se que a leitura é capaz de incitar a imaginação do leitor, abrindo espaço para diálogos e aproximações com a arte narrativa. No caso da literatura infantil, Silva (2012, p. 5) afirma que se trata de "[...] um instrumento para estimular a imaginação e a criatividade da criança, na medida em que promove situações para isso, como a brincadeira do faz de conta, demonstrando cenas de uma história contada", entre outras práticas possíveis no desenvolvimento da leitura literária com crianças. Para Lobo e Goulart (2017) a leitura literária, pode ser compreendida como:

[...] forma de expressão da linguagem, configura-se como uma atividade para além da ludicidade, da integração cultural e social; torna-se essencial ao ser humano na relação consigo mesmo, com o outro e com o mundo que o cerca. A leitura gera sonhos e fantasias, permite às crianças uma aproximação com a arte estética e mística do imaginar, torna-se a companhia e o amparo, conforme a epígrafe, frente aos mistérios que as cercam. (LOBO; GOULART, 2017, p. 122). 


\section{OO DEVIR EDUCAÇÃO}

ISSN: 2526-849X

De acordo com as autoras, pode-se compreender que a leitura literária tem um papel de destaque no desenvolvimento afetivo, cognitivo e da criticidade para a criança. Nesse sentido, o letramento literário pode ser uma prática desde o início da vida escolar, com crianças pequenas, pois não se restringe apenas às crianças que leem, mas atinge aos leitoresouvintes por meio da leitura realizada pelo professor, por um adulto ou por uma criançaleitora mais experiente.

O letramento literário tem como objetivo de leitura “[...] o desvelamento das informações do texto e pela aprendizagem de estratégias de leitura para chegar à formação do repertório do leitor [...]", conforme nos apontam Souza e Cosson (2011, p. 103). Nesse sentido, os autores destacam que um dos procedimentos a ser considerado para alcançar este objetivo é fazer o exame de detalhes do texto, sua contextualização e sua inserção em um diálogo com outros textos, o que também pode ser realizado em atividades de leitura pelo professor e em rodas de conversas.

\section{Ação mediadora da leitura literária na escola}

Compreendendo a leitura literária como uma prática de ampla importância para o desenvolvimento social, cultural, afetivo e cognitivo do aluno, verifica-se que o planejamento e a elaboração de projetos de leitura realizados pelo professor, requerem que se tenha consciência da dimensão da potencialidade dessa atividade na rotina escolar.

Nesse sentido, cabe ressaltar que o professor, o adulto ou a criança mais experiente compreendam o papel de atuação como mediador entre o leitor e o livro, pois é esse mediador quem favorece a interlocução, muitas vezes, a partir da escolha da obra a ser lida e trabalhada, em sala de aula, como também dos modos de apresentação e de leitura daquela determinada narrativa aos alunos.

A ação mediadora estabelece a relação da criança com a literatura infantil, servindo como exemplo para a interação com os livros, mostrando para a criança as opções a serem lidas, a maneira adequada de se manusear o objeto, promovendo o diálogo e a reflexão sobre 
o conteúdo literário, além de representar uma importante influência da oralidade ao ato de ler ou de contar uma história.

Nessa direção, destaca-se que o mediador deve saber usar as possibilidades e modalidades da voz ao ler e/ou contar uma história, independente do ouvinte ser adulto ou criança, alfabetizado ou não: “[...] sussurrar quando a personagem fala baixinho [...] levantar a voz quando uma algazarra está acontecendo, ou falar de mansinho quando a ação é calma [...] e usar humoradamente as onomatopeias, os ruídos e os espantos”, são estratégias de leitura necessárias para que haja a oportunidade do ouvinte adentrar na história, imaginar o que está sendo narrado, fantasiar sobre o que ouve (ABRAMOVICH, 1997, p. 21).

Logo, ao participar de um momento de leitura literária e/ou contação de histórias, a criança pode se sentir estimulada a criar, a pensar, a imaginar, a brincar, a escrever e tantas outras ações porque, segundo Abramovich (1997), ouvir uma boa história é fonte de prazer e de deleite. Como parte de um processo de criação imaginária, a leitura permite que a criança se desenvolva estimulando sua inventividade e autonomia que, por sua vez, produzem saberes e conhecimentos.

A formação do professor-mediador deve enfatizar a consciência de práticas como o ato de ler ou de contar histórias. De acordo com Mello (2016), as experiências originadas a partir do ato de ler são transformadoras, pois impulsionam o desenvolvimento dos sujeitos leitores compreendendo que o prazer pela leitura é compartilhado e vivenciado também por quem escuta. Dessa maneira, a autora explica que ler por deleite pode ser socialmente ensinado, uma vez que a criança aprende ao observar o outro, ao vivenciar o prazer no processo de leitura do outro, ou seja, “[...] internalizamos o prazer pela leitura quando o vivenciamos coletivamente" destacando aqui a relevância do papel do adulto mediador na prática da leitura literária (MELLO, 2016, p. 45).

Apesar das diversas possibilidades de se trabalhar a leitura literária, Cosson (2014) deixa claro que não há uma receita pronta para se realizar ações leitoras a partir do letramento literário, o qual pode ser efetivado de maneiras diversas, respeitadas suas características fundamentais, que são: o contato direto do leitor com a obra; construção de uma comunidade de leitores, onde leituras são compartilhadas, havendo circulação de textos e respeito pelo interesse e nível de desenvolvimento de leitora do aluno; ter como objetivo a ampliação do repertório literário; realização de atividades sistematizadas e contínuas direcionadas para o desenvolvimento da competência literária. Consideradas essas ações procedimentais, o 
professor-mediador cumpre o papel de formar o leitor literário, desenvolvendo as competências apropriadas.

Porém, efetiva-se o letramento literário a partir de ações como: a oportunidade cedida ao aluno de manter contato direto com a obra; a criação de uma comunidade de leitores com espaço e respeito para os diferentes gostos e necessidades e, finalmente, a possibilidade de ampliação do repertório de obras disponíveis aos leitores. Para tanto, é necessário que o professor-mediador esteja ciente de que a literatura está presente em vários meios e suportes, bem como, saber que lhe cabe a acolha dentre as diferentes formas de manifestações do texto, aquele que melhor atende ao objetivo proposto para a leitura planejada (COSSON, 2014).

Vê-se que a literatura infantil se transforma desde o início da sua história, são contínuas, pois estão em movimento e se modificam de acordo com a época e com o espaço. E é neste sentido que Dalcin (2012, p. 9-10) discute a necessidade de que "[...] as instituições escolares, as formações de professores, sejam iniciais ou continuadas, acompanhem tais transformações para o benefício do leitor infantil que, muitas vezes, tem acesso a livros apenas pela figura do professor".

\section{Promovendo ações e relações por meio da prática da leitura literária}

Por meio dos subsídios do relato de experiências, desenvolvidas por uma professora do $2^{\circ}$ ano do Ensino Fundamental, com crianças em fase de alfabetização, apresenta-se uma reflexão das ações de leitura literária que implementou propostas de atividades relativas à leitura literária e à contação de histórias, durante o ano letivo de 2016 e 2017, com base na perspectiva teórica de letramento literário de Cosson $(2014,2016)$.

A professora atua na rede pública municipal de ensino há mais de 19 anos, com experiências na educação infantil e anos iniciais do ensino fundamental, com ênfase na alfabetização. Com formação em magistério e graduação em licenciatura em Filosofia, a professora manifestou uma busca constante por conhecimentos referente às propostas de ensino, com vistas ao aprimoramento de sua prática pedagógica.

Em relação ao trabalho pedagógico com leitura de livros de literatura infantil, a professora revela que, inicialmente, tal prática ocupava um papel secundário na sua rotina de 
planejamento das atividades escolares. A realização da leitura literária, concretizada na ação de ler ou de contar a histórias, era, até então, feita sem a devida reflexão ou consciência de sua potencialidade, não valorizando a importância de tais práticas. A prática leitora acontecia somente quando havia tempo ocioso, ou como suporte pedagógico, para introduzir algum tema específico a ser trabalhado em conteúdos de Ciências, História ou Geografia. Algumas vezes, os textos literários eram cortados ou adaptados com a finalidade de introduzir palavras, sílabas, frases, ou ainda, para noções de Matemática, ao explorar os numerais ordinais, a quantificação, sequenciação, operações, entre outros temas, constituindo-se, assim, em uma prática inadequada da escolarização da literatura infantil, conforme acredita Soares (2011).

Esse repensar das práticas de leitura surgiu a partir de reflexões teórico-metodológicas oportunizadas pelos encontros de estudos do NELLE (Núcleo de Estudos de Linguagem, Leitura e Escrita), do Departamento de Educação da UFLA. Sendo assim, mobilizada pela formação continuada organizada e pelos encontros de estudos do NELLE, a professora implementou em sua prática pedagógica, em sala de aula, atividades diárias de leitura literária. Desde então, busca transformar o contexto de leitura e de narração de histórias, de modo a dar um novo sentido ao papel do livro e da literatura infantil no cotidiano escolar.

A diversidade de ações propostas pela professora ao longo do ano letivo abarcou a ideia de que a literatura infantil, nas práticas de leitura literária e de contação de histórias, oferecia inúmeras possibilidades de serem trabalhadas em sala de aula, e que além disso, poderiam contribuir de forma expressiva no desenvolvimento das múltiplas linguagens das crianças, do texto nas dimensões: visual, oral, musical, escrito, artístico, dentre outros (SILVA, 2012).

As leituras foram realizadas em todos os dias letivos, no início da aula, com uma preparação prévia pela professora a partir da escolha do texto e da forma como seria lida a história. No início, causou desconstrução dos modos de ler já vivenciados pelas crianças, com aceitabilidade da proposta pedagógica, lia-se e conversava-se sobre o texto.

Sabendo que a literatura infantil alcançaria a criança, de modo mais intenso, por intermédio de um mediador de leitura, a professora passou a assumir um posicionamento de mediadora, pois ao ler uma história para uma criança, mesmo uma criança não alfabetizada, essa professora proporciona um momento de ensinamento e de diversão, porque a narração é uma arte. Além disso, “[...] ler narrativas para uma criança não alfabetizada é estimulá-la na 
sua futura leitura e escrita, desenvolvendo nela o valor da oralidade, a importância da linguagem oral" (SILVA, 2012, p. 6).

Segundo a perspectiva da professora, inserir uma proposta pedagógica diferenciada e constante requereu determinação e persistência, na busca de um novo modo de olhar, de certa forma, mais atento e sensível, tanto para a criança quanto para o agir pedagógico, o que a motivou a introduzir mudanças, buscando incentivar o gosto pela leitura e desenvolver estratégias de compreensão da leitura realizada.

A prática da leitura solicita posicionamentos dos leitores, seja do professor ou dos alunos. Por isso, no início do ano letivo, a professora realizou uma roda de conversa com as crianças, em que discutiu como deveriam se comportar para obterem mais atenção no que estava sendo lido, ressaltando que atitudes poderiam aderir para se tornarem ainda melhores leitores-ouvintes. Desse modo, relembrava as atitudes discutidas antes de se iniciar cada leitura, desenvolvendo uma proposta pedagógica em momentos que aconteciam antes, durante e depois da leitura literária, conforme orienta Solé (1998).

Antes da leitura, o livro a ser lido era apresentado para todos, momento em que se explorava a capa, observando as imagens, o título, o autor e o ilustrador. A professora buscava no livro as informações sobre o autor e, neste momento, também se levantavam as hipóteses sobre qual tema seria abordado na história, a partir da observação da imagem da capa e do título da obra.

As crianças-leitoras levavam em conta aspectos relevantes para a produção de sentidos a partir do potencial interpretativo materializado no suporte literário, por meio de uma reflexão sobre a linguagem da literatura, como deleite e fonte informativa no âmbito educacional, de modo a observarem elementos que reiteram a força dos livros como instrumento pedagógico.

Nesse momento inicial, foi possível identificar o trabalho que antecede a realização da leitura literária, segundo nos descreve Solé (1998). A leitura decorre de estratégias em que são acionados conhecimentos prévios, conforme mencionada por Souza e Cosson (2011, p. 104), "[...] como a estratégia 'guarda-chuva', pois, a todo momento, os conhecimentos que o leitor/ouvinte tem sobre o que está sendo lido/ouvido são ativados [...]”, o que também observou-se nas interações estabelecidas durante toda a leitura, nas pausas para comentários. Conforme Paiva e Oliveira (2010, p. 30) “[...] para que haja êxito no processo de formação de leitor, o educador deve ter clareza de sua metodologia com a literatura infantil em sala de 
aula, despertar questionamentos e promover a construção de novos significados."

Desse modo, ao assumir a posição de mediadora da leitura, a professora não somente valoriza, mas também encoraja a participação dos alunos, de modo que haja a promoção da interação e do diálogo entre os leitores e o texto lido ou narrado. A prática pedagógica da leitura parte do princípio de que "[...] implica troca de sentidos não só entre o escritor e leitor, mas também com a sociedade onde ambos estão localizados, pois os sentidos são resultado de compartilhamentos de visões do mundo entre os homens no tempo e no espaço", afirma Cosson (2007, p. 27 apud PAIVA; OLIVEIRA, 2010, p. 32).

Percebendo a importância da reflexão sobre o texto lido e da implementação de estratégia de leitura, aos poucos, a professora foi introduzindo mudanças no fazer pedagógico ao longo de cada leitura realizada, na intenção de explorar o levantamento de hipóteses e a participação mais ativa das crianças no contexto da narrativa. Como ressaltado por Souza e Cosson (2011, p. 104) "“...] a atividade de acionar essas informações interfere diretamente na compreensão durante a leitura [...]".

No momento de realização da leitura, a professora utilizava uma proposta de incentivo à curiosidade das crianças pelo enredo e contexto da narrativa. Por exemplo, com uma pequena ficha de papel, cobria-se o título e a partir das imagens as crianças deveriam pensar sobre o que, qual assunto a história discorreria. Logo após, se retirava a ficha e conhecendo o título, novas hipóteses eram apresentadas relacionando o título com imagens. Essas hipóteses eram retomadas quando a leitura da obra se encerrava e as crianças confrontavam suas hipóteses iniciais com a leitura realizada. As crianças, também, foram incentivadas a analisarem o título do livro, dizendo se concordavam ou não. Buscavam argumentos e justificavas para manter ou propor outro título, outro final, outra atitude para um determinado personagem, outra proposta de ilustração para a capa ou para a história lida.

Durante toda a leitura as crianças interagiam com texto, buscando sentido para acontecimentos, observando e comentando as imagens da obra lida. A partir dessas atitudes das crianças, a professora introduzia questionamentos durante a leitura, fazendo paradas para que as crianças pudessem prever os próximos acontecimentos e depois confrontavam sua previsão com o que realmente acontecera. Tal proposta possibilitou às crianças acionarem a estratégia de conexão, citada por Souza e Cosson (2011), em que relacionavam o contexto da narrativa, ordenando fatos e ações de forma coerente, em aproximação com outros textos lidos, com situações e/ou com vivências reais. 
Queirós (2012) chama atenção para o fato de que um texto literário nos dá a oportunidade de dialogar com quem somos na realidade. O sujeito-leitor passa a ter suas lembranças, sentimentos e imaginação acionadas pelas palavras escritas por um outro sujeitoleitor. Assim, por meio de um texto que descontextualiza, que exige entendimento, que confronta o que sabe a respeito do tema, que convida a um posicionamento, oportuniza-se uma experiência de leitura, pois provoca a interação, a integração e a interlocução entre o leitor e o texto.

A atividade proporcionou que as crianças desenvolvessem estratégias de inferência, conforme discutida por Solé (1998), como uma proposta que move o leitor antes, durante e após a leitura. A inferência constitui-se na “[...] interpretação de uma informação que não está explícita no texto [...]", bem como o desenvolvimento da estratégia de visualização, na qual as palavras do texto se tornam ilustrações em na mente do leitor. (SOUZA; COSSON, 2011, p. 104). Dessa maneira, compreende-se que somente ser alfabetizado e ler um livro ou ser capaz de ouvir uma história não forma, necessariamente, o aluno como um leitor literário, "[...] mas sim, na medida em que são desafiados por leituras progressivamente mais complexas e que compartilham suas visões de mundo [...]”. (PAIVA; OLIVEIRA, 2010, p. 32).

Outro momento, introduzido na rotina da sala de aula, foi o ato de compartilhar leituras de livros de literatura infantil. A professora, juntamente com os alunos, decidiu que, uma vez por semana, realizaria uma roda de conversa em que cada criança apresentaria o livro levado para casa. Cada aluno procuraria contar a história, resumidamente, de modo a despertar nos colegas o interesse por aquela obra. No começo do ano as crianças demonstraram nervosismo, timidez e dificuldade em se expressarem oralmente com coerência e coesão, com objetividade e com desenvoltura da linguagem.

Porém, a partir da frequência da atividade a professora evidenciou que, durante o processo, houve um avanço na articulação e na expressividade da linguagem da maioria dos alunos daquela turma, visto que demostraram ser capazes de relatar com mais clareza o contexto da narrativa, argumentar sobre o assunto do livro, com maior preocupação em descrever informações contidas na obra em questão, como o nome do autor e do ilustrador. Na roda de apresentação e comentário sobre os livros, ao perceber que já haviam lido a obra em exposição, as crianças interagiam compartilhando opiniões e dicas sobre a história compartilhada.

Ao introduzir propostas de leitura literária na rotina diária, a professora percebeu que 
ao final das aulas as crianças, quando podiam ler individualmente os livros da caixa do Programa Nacional do Livro Didático (PNLD), demonstraram atitudes diferentes das observadas no início do ano letivo. Passaram a se sentar em duplas para apreciar uma obra e, neste momento, a criança que lia com mais fluência narrava a história para o outro que ainda estava em processo de desenvolvimento das habilidades leitoras, outras vezes os alunos procuravam realizar a leitura juntos de forma alternada.

Além disso, a professora percebeu que as crianças se mostravam mais atentas aos detalhes das imagens dos livros, relacionando-as com o texto escrito e lido. Procuraram também as páginas que falavam sobre o autor e sobre o ilustrador, em seguida comparavam obras do mesmo autor, como por exemplo, a leitura realizada de dois livros da autora e ilustradora Eva Furnari, “A Bruxinha Atrapalhada" e "Cocô de passarinho". Os alunos, após verem os dois livros identificaram que era da mesma autora e fizeram a seguinte observação: "O livro da 'Bruxinha' é feito só de imagens e do 'Cocô de passarinho' tinha texto escrito".

Com base nesse episódio, a professora notou outras mudanças no comportamento das crianças com relação ao livro e à leitura. Em meio ao processo de leitura literária, em sala de aula, mesmo quando não eram feitas as intervenções com a iniciativa da professora, as próprias crianças já faziam sozinhas pausas para o levantamento de hipóteses ou comentários relativos à obra que em leitura.

Duas falas das crianças exemplificam o que os momentos de leitura literária significaram para elas. Uma das falas ocorreu quando um aluno chegou à mesa da professora, depois do momento de leitura literária, e disse com entusiasmo: "Professora, sabe por que é bom ouvir histórias e ler os livros? Porque, assim, a nossa cabeça fica cheia de histórias!’”

Outro fato que chamou a atenção da professora foi quando, depois de três dias sem um momento de leitura literária e de contação de histórias, um aluno se aproximou, ao final da aula, com feição entristecida e ao ser questionado sobre o que acontecera, respondeu com outra pergunta: "Professora, você não vai ler mais histórias pra gente?”.

A fala dessas crianças indica que a prática da atividade de leitura literária e de contação de histórias, representa mais do que um momento de aprendizagem e de ampliação do repertório, torna-se um momento de encontro, conforme descreve Lajolo (2009), que desencadeia relações de afetividade. Nesse sentido, pode-se afirmar que, quando um adultomediador lê para uma criança, este incorpora a história com seu tom de voz, com seus gestos, seu olhar, de modo que a criança tem suas emoções provocadas, encontra-se entregue às 
palavras, sente-se convidada a penetrar no enredo e, mesmo com seu corpo estático, sente-se como uma participante da história narrada (LOBO; GOULART, 2017, p. 134).

A prática de leitura literária realizada pela professora, em sala de aula, demonstra uma proposta pedagógica em que ocorre a relação entre literatura e ensino, coerente com as características fundamentais do letramento literário proposto por Cosson (2014). A proposta pedagógica permitiu o contato direto da criança leitora-ouvinte com a obra, por meio da materialidade impressa do livro; propiciou um espaço onde as leituras das crianças foram compartilhadas com os colegas, respeitando o interesse e nível de desenvolvimento de leitura de cada um, como também, promoveu a ampliação do repertório literário. Em nenhum momento, o espaço-tempo da leitura em sala de aula deixou de ser sistematizado e contínuo direcionado para o desenvolvimento da competência leitora.

Dessa forma, cabe refletir sobre o modo como as atividades de leitura literária desenvolvidas de forma intencional, planejada e organizada por meio de ações pedagógicas, correlacionam teoria e prática, atribuem à literatura um papel de destaque na esfera escolar. Sendo assim, é fundamental que as práticas de leitura literária aconteçam com a finalidade de proporcinar um momento prazeroso, de apreciação estética e reflexiva com e sobre o texto, com “[...] o compromisso da construção do conhecimento, já que na escola, a literatura é um lócus de conhecimento e deve ser desenvolvida de maneira correta com o objetivo de formar o sujeito intelectualmente e eticamente mais humanizado". (PAIVA; OLIVEIRA, 2010, p. 32).

\section{Considerações finais}

Por ser a atividade de leitura reconhecida como uma das competências culturais mais valorizadas em uma sociedade letrada, tem-se a necessidade de formar leitores proficientes, pois ler torna-se uma condição fundamental para o exercício da cidadania plena. Diante disso, a escola exerce um papel significativo no processo de formação de leitores.

A leitura literária, como parte da pluralidade das ações de letramento, requer um tratamento diferenciado pela instituição escolar, como afirmam Souza e Cosson (2011), pois se refere ao processo de se apropriar da literatura enquanto linguagem, como ação contínua e 
múltipla (COSSON, 2014). Dessa forma, a literatura se mostra como uma das formas de alimentar e exercitar a linguagem, na dimensão dialógica, expressiva, artística e estética.

Assim, a partir do relato de práticas de leitura com livros de literatura infantil, tem-se a visibilidade de um fazer pedagógico que estimula ações leitoras no contexto da sala de aula. A reflexão proposta sinaliza a contribuição das práticas de letramento literário no processo de formação de leitores, diante do qual a professora buscou ações e atuações antes, durante e após a leitura. Observa-se que ocorreu um repensar e um reposicionamento frente às atividades da rotina em sala de aula, à leitura diária, à finalidade das rodas de leitura realizadas, às intervenções efetivadas com cada obra escolhida, ao inserir práticas pedagógicas em interlocução com as discussões teóricas, constituídas na perspectiva de letramento literário, conforme apresentado por Cosson $(2014,2016)$.

Constata-se o quanto a ação e a atuação do professor-mediador se mostram determinantes para que os alunos se tornem sujeitos-leitores, por meio do contato com as obras literárias, do posicionamento argumentativo e reflexivo sobre a narrativa e do compartilhamento de histórias lidas. A aproximação, a interação e a interlocução da criança com livros de literatura infantil permitem "[...] desenvolver o hábito e o prazer pela leitura, desenvolver as capacidades orais e ampliar a compreensão de mundo de forma intelectual e crítica, e sobretudo, contribui para a constituição da criança como narradora por meio das histórias que constituem essa arte". (SILVA, 2012, p. 3-4).

Com base em Silva (2012, p. 6), aponta-se a necessidade dos professores se conscientizarem do seu papel como de mediador de leitura, pois na ação de mediação se planeja, executa e se propicia momentos que potencializam a criatividade, a imaginação, a expressividade, a socialização e a interação do sujeito-leitor com a obra, com outros leitores, com outras leituras e consigo mesmo, de modo a favorecer uma experiência de leitura.

As mudanças introduzidas no relato de experiência da professora, ainda que discretas, parecem coerentes com as características fundamentais de letramento literário referidas por Cosson (2014) e sinalizam ações e atuações mediadoras de uma prática pedagógica que envolve a relação entre a literatura e o ensino, de modo a favorecer e encorajar o desenvolvimento de estratégias de leitura com crianças em fase da alfabetização. Dessa maneira, verifica-se que o professor-mediador se constitui como um agente fundamental no movimento de apropriação da leitura literária, seja por meio de uma obra impressa, de um livro ilustrado ou um livro-imagem, adentra-se e permeia-se a vida do sujeito-leitor. E a 


\section{OO DEVIR EDUCAÇÃO}

ISSN: 2526-849X

escola se torna um espaço de gerenciamento de ações e atuações pedagógicas que potencializam este processo.

Portanto, a função do professor-mediador se mostra determinante no processo de formação de leitores, por atuar antes, durante e depois da ação leitora, por promover práticas de leitura em sala de aula, seja na escolha da obra, na organização dos materiais auxiliares na realização da leitura, seja no planejamento de propostas de intervenção com e sobre o texto lido, entre outras. Nesse caso, o professor-mediador é o sujeito que planeja, pensa e organiza, inclusive o que precede o ato de ler, como a "[...] diversificação de textos a serem trabalhados em sala de aula [...]" (GUEDES-PINTO, 2017, p. 98).

As ações pedagógicas com a leitura literária articuladas de forma mais consciente e planejadas contribuem com o processo de formação de sujeitos-leitores, haja vista que a relação ensino e literatura compreende dimensões extensivas ao conteúdo curricular, por envolver a dimensão discursiva e dialógica da linguagem e por envolver a complexidade da ação leitora, pois segundo Queirós (2012, p. 83), “[...] ler é experimentar novos sentimentos, é buscar outras referências, é desobstruir e deixar passar a palavra do outro que tanto incomoda as nossas certezas. Teria a escola outra função maior do que esta de nos tornar posseiros da diferença?".

\section{Referências}

ABRAMOVICH, Fanny. Literatura Infantil: Gostosuras e bobices. São Paulo: Scipione, 1997.

BAKHTIN, Mikhail. Estética da criação verbal. 4. ed. Trad. Paulo Bezerra. São Paulo: Martins Fontes, 2003.

. Marxismo e filosofia da linguagem. Trad. Michel Lahud e Yara Frateschi Vieira. 13. ed. São Paulo: Hucitec, 2012.

BRAIT, Beth. Bakhtin e a natureza constitutivamente dialógica da linguagem. In:

(Org.). Bakhtin, dialogismo e construção de sentido. Campinas: Editora da Unicamp, 2005. p.87-98.

CANDIDO, Antonio. O direito à literatura. In: . Vários Escritos. 5 ed. Rio de Janeiro: Ouro sobre Azul/ São Paulo: Duas Cidades, 2011. p. 169-19. 
COSSON, Rildo. Letramento literário. In: FRADE, Isabel C. Alves da Silva et al. Glossário CEALE: termos de alfabetização, leitura e escrita para educadores. Belo Horizonte: UFMG/Faculdade de Educação, 2014. p. 185-186.

COSSON, Rildo. Letramento literário: teoria e prática. 2.ed. São Paulo: Contexto, 2012.

DALCIN, Andrea Rodrigues. A leitura do livro ilustrado e livro imagem: da criação ao leitor e suas relações entre texto, imagem e suporte. IX ANPED Sul Seminário de Pesquisa em Educação da Região Sul. 2012.

GUEDES-PINTO, Ana Lúcia. Práticas de leitura: papel da formação continuada e seus impactos na alfabetização. In: GOULART, Ilsa do Carmo Vieira; MAZIERO, Maria das Dores Soares; CARVALHO, Silvia Aparecida Santos de (Org.). Leitura, escrita e alfabetização: a pluralidade das práticas. Campinas: Leitura Crítica, 2017. p. 96-105.

LAJOLO, Marisa Philbert. Usos e abusos da literatura na escola: Bilac e a literatura escolar na República Velha. Rio de Janeiro: Globo, 1982.

LAJOLO, Marisa. O texto não é pretexto. Será que não é mesmo? In: ZILBERMAN, Regina; RÕSING, Tania (Org.). Escola e leitura: velha crise, novas alternativas. São Paulo: Global, 2009. p. $99-112$

LOBO, Dalva de Souza; GOULART. Ilsa do Carmo Vieira. O leitor e a leitura literária: do projeto à fruição. In: GOULART, Ilsa do Carmo Vieira; MAZIERO, Maria das Dores Soares; CARVALHO, Silvia Aparecida Santos de (org.). Leitura, escrita e alfabetização: a pluralidade das práticas. Campinas: Leitura Crítica, 2017. p. 122-137.

MELLO, S. A. Leitura e literatura na infância. In: GIROTTO, C. G. G. S.; SOUZA, R. J. de. Literatura e Educação Infantil: Livros Imagens e Práticas de Leitura. Campinas: Mercado das Letras, 2016. vol. 1. p.39-56.

PAIVA, Silvia Cristina Fernandes; OLIVEIRA, Ana Arlinda. A literatura infantil no processo de formação do leitor. Cadernos da Pedagogia, São Carlos, v. 4, n. 7, p. 22-36, jan./jun. 2010. Quadrimestral. Disponível em: http://www.cadernosdapedagogia.ufscar.br/index.php/cp/article/viewFile/175/101. Acesso em: 28 abr. 2020.

PIMENTEL, Lucia Gouvêa; CUNHA, Evandro José Lemos da; MOURA, José Adolfo. Propostas Curriculares - Arte para o ensino fundamental e médio, 2006. Disponível em: https://docplayer.com.br/19656892-Secretaria-de-estado-de-educacao-de-minas-geraisensinos-fundamental-e-medio-arte-proposta-curricular.html. Acesso em: 27 ago. 2020.

QUEIRÓS, Bartolomeu Campos de. Ler é deixar o coração no varal. In: QUEIRÓS, Bartolomeu Campos de. Sobre ler, escrever e outros diálogos. Belo Horizonte: Autêntica, 2012. p. 89-97.

ROJO, Roxane. Letramentos múltiplos, escola e inclusão social. São Paulo: Parábola Editorial, 2009. 
SILVA, Maria de Jesus Marques. A literatura infantil como recurso para aquisição da linguagem da criança. In: ENCONTRO NACIONAL DE DIDÁTICA E PRÁTICÁS DE ENSINO, 2012, Campinas. XVI ENDIPE. Campinas: Junqueira \& Marin, 2012. p. 1-12. Disponível em: http://docplayer.com.br/165541303-Palavras-chaves-literatura-infantillinguagem-oral-narrativas.html. Acesso em: 28 abr. 2020.

SOARES, Magda. Letramento: um tema em três gêneros. 2. ed. Belo Horizonte: Autêntica, 1999. 128p.

A escolarização da literatura infantil e juvenil. In: EVANGELISTA, Aracy Alves Martins; BRANDÃO, Heliana Maria Brina; MACHADO, Maria Zélia Versiani (Org.). Escolarização da leitura literária. 2. ed. Belo Horizonte: Autêntica, 2011.

SOUZA, Renata Junqueira; COSSON, Rildo. Letramento Literário: uma proposta para a sala de aula. Objetos Educacionais, UNESP, n.15, p.101-107, ago. 2011. Disponível em: http://acervodigital.unesp.br/handle/123456789/40143. Acessado em: 04 jan. 2020.

SOLÉ, Isabel. Estratégias de leitura. Trad. Cláudia Schilling. 6. ed. Porto Alegre: Artmed, 1998.

STREET, Brian. Letramentos sociais: abordagens críticas do letramento no desenvolvimento, na etnografia e na educação. Trad. Marcos Bagno. São Paulo: Parábola Editorial, 2014.

ZILBERMAN, Regina. A leitura e o ensino da literatura. São Paulo: Contexto, 1988. 